\title{
Atmospheric reaction to the manifestations of the geodynamic activity of the Sulawes phenomenon according to satellite data
}

\author{
Valentin Kashkin ${ }^{1}$, Roman Odintsov ${ }^{1}$, Tatyana Rubleva ${ }^{1}{ }^{*}$, Konstantin Simonov $^{2}$, and Julia \\ Tsup $^{1}$ \\ ${ }^{1}$ Siberian Federal University, Krasnoyarsk, 660074, Russia \\ ${ }^{2}$ Institute of Computational Modeling SB RAS, Krasnoyarsk, Russia
}

\begin{abstract}
Using ATOVS satellite data (NOAA / POES) atmospheric disturbances that arose in the equatorial zone of Indonesia in the fall of 2018 were studied as a reaction to the geophysical manifestations of the geodynamic activity of a strong earthquake with a magnitude of $M=7,5$. An archive of satellite information has been formed. A technique has been developed for analyzing the temperature of profiles during strong seismic activity of the Sulawes phenomenon. The atmospheric effects over the seismically active region of this earthquake were studied. It was found that in the troposphere during the study period anomalies with lower temperatures are observed above the epicenter region of the Indonesian earthquake and thermal anomalies with elevated temperatures are formed in the lower stratosphere.
\end{abstract}

\section{Introduction}

The study is devoted to an actual problem - the study of the effects of the interaction between the lithosphere and the atmosphere during geodynamic activity. Satellite data make it possible to detect phenomena in a disturbed environment at different stages of geophysical intensification in the form of variations in temperature, pressure and humidity on various isobaric surfaces.

In this paper we consider the results of a study of atmospheric disturbances that arose in the fall of 2018 over the seismically active region of Sulawesi Island (Indonesia) based on remote sensing data ATOVS (Advanced TIROS Operational Vertical Sounder, NOAA / POES). In this geodynamically active place of the Asia-Pacific region in SeptemberOctober 2018 three catastrophic geophysical events occurred consecutively during the week: an earthquake with $\mathrm{M}=7,5$, a tsunami in Palu Bay and an eruption of the Soputan volcano $[1,2]$. The aim of the study is to obtain estimates of the geophysical manifestations of the Sulawes phenomenon.

\footnotetext{
* Corresponding author: tvrubleva@mail.ru
} 


\section{Analysis of seismic activity in the region}

The seismically active region of Sulawesi Island is located in the south-western part of the Pacific subduction zone in the area of interaction between the Australian, Eurasian and Philippine tectonic plates $[3,4]$.

September 28, 2018 on about Sulawesi Island at a depth of 10-20 km seven seismic events with magnitudes of $5,8 \leq \mathrm{M} \leq 7,5$ occurred. The strongest of them with $\mathrm{M}=7,5$ was recorded at 10:02:45 (UTC) with a focal depth of $20 \mathrm{~km}[1,5]$. The coordinates of the epicenter of this strong earthquake, which occurred approximately $80 \mathrm{~km}$ north of Palu, are $0.256^{\circ} \mathrm{S}, 119.846^{\circ} \mathrm{E}$. The focal region was $200 \mathrm{~km}$ long and $20 \mathrm{~km}$ wide. The geodynamic features of seismic events $M=7,5$ are considered in detail in $[2,6]$. The likely cause of the Sulawes earthquake was the movement of the earth's crust along the Palu-Koro Fault.

According to IRIS [7] from September 21 to October 4, 201849 seismic events with magnitudes of $4,3 \leq M \leq 5,8$ were recorded in the aftershock field of the Sulawes earthquake. The distribution of magnitudes of foreshocks and aftershocks with the development of the seismic process in time is shown in Fig. 1. Most of the hypocenters of these foreshocks and aftershocks were located at a depth of 10-20 km. The strongest foreshock of magnitude $M=6,1$ was recorded 3 hours before the main seismic event $M=7,5$. As can be seen from Fig. 1 after the main shock in the focal region, the aftershock activity decreases, which is described by the Omori law [8].

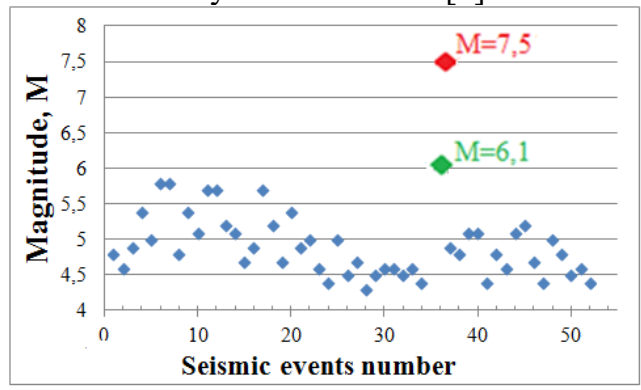

Fig. 1. Forshock and aftershock sequence of earthquake seismic events $M=7,5$.

The chronology of geophysical events on September 28 shows that 7-12 minutes after the earthquake with $M=7,5$ on the coast of about. Sulawesi hit the first tsunami waves $[1,2]$, two waves were recorded at intervals of 5 and 10 minutes. Along the coast of the island the wave height varied from 1.5 to $2 \mathrm{~m}$. In the Palu Bay surrounded by mountains with peaks reaching up to $2000 \mathrm{~m}$ and which became a "funnel" for these waves, the tsunami splash height varied from 6 to $10 \mathrm{~m}$.

After 4 days on October 2 at 22:46 (UTC) an increase in the amplitudes of seismic signals in the northeastern part of Sulawesi Island in the area of the Soputan stratovolcano with coordinates $1^{\circ} 108^{\prime} \mathrm{N}, 124^{\circ} 73^{\prime} \mathrm{E}$ [9]. His eruption occurred on October 3 at 08:44 UTC. Volcanic Explosivity Index [10] Soputan which describes the relative measure of explosiveness of volcanic eruptions and is used to estimate their impact on the atmosphere is 3. According to seismic information this geophysical event lasted 6 minutes [1]. As a result of the eruption, an ash plume formed rising to an altitude of $5.8 \mathrm{~km}$ (above sea level) and shifting towards the west and north-west.

The interconnectedness of the above natural disasters made it possible to introduce the term Sulawes phenomenon to characterize these geophysical events. As a result of the analysis of the development of seismic processes carried out according to the USGS and IRIS catalogs [5, 7] the period of active existence of the Sulawes phenomenon was determined - this is the time interval from September 21 to October 4. 


\section{Analysis of the reaction of the atmosphere to the developments of geodynamic activity}

In our work we studied in detail the effects of the atmospheric reaction on the geophysical developments of the geodynamic activity of a strong earthquake with a magnitude of $\mathrm{M}=7,5$ in autumn 2018 obtained using the ATOVS instrument complex and presented on the site [11]. ATOVS equipment is designed to restore atmospheric meteorological fields at different heights. The ATOVS instrument complex measures the intensity of the Earth's own radiation in individual absorption bands of gases in the infrared and radio ranges [12]. The ATOVS hardware span is $2,250 \mathrm{~km}$. The spatial resolution is 20$50 \mathrm{~km}$ horizontally and 2-3 km vertically. The standard deviation of ATOVS temperature data from radiosonde readings is $1.3 \mathrm{~K}$.

Based on the ATOVS satellite information we compiled a data archive that contained temperature values at isobaric levels of 1000-100 hPa in a disturbed atmosphere over the Sulawes seismically active region.

Based on the methodology for analyzing vertical temperature profiles described in $[13,14]$ in this work we studied variations in temperature, pressure and humidity in a perturbed atmosphere starting from the surface layer $(\sim 0.5 \mathrm{~km})$ to the lower stratosphere $(\sim$ $16 \mathrm{~km})$. Separate temperature profiles at isobaric levels of $950 \mathrm{hPa}(\sim 0.5 \mathrm{~km}), 350 \mathrm{hPa}(\sim$ $8.0 \mathrm{~km}), 250 \mathrm{hPa}(\sim 10.0 \mathrm{~km})$ and $100 \mathrm{hPa}(\sim 16.0 \mathrm{~km})$ are presented in Fig. 2. The arrow indicates the earthquake date $\mathrm{M}=7,5$. On the horizontal axis, are plotted the measurement moments in increments of 3 hours from September 15 to October 7, 2018.

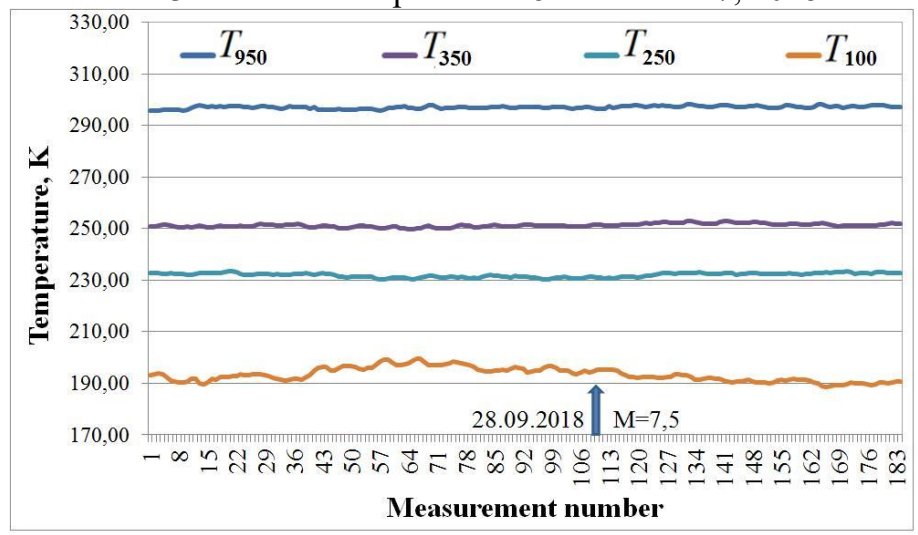

Fig. 2. Variations of temperature profiles at isobaric levels of 950, 350, 250 and $100 \mathrm{hPa}$ over the focal region of the Sulawes earthquake.

As can be seen from Fig. 2 graphs of the temperature series $T$ during the preparation of earthquakes during the main shock and during the aftershock activity in the troposphere and lower stratosphere do not change significantly and reflect the uniform temperature regime of the equatorial zone of Indonesia.

Using correlation analysis estimates of consistent temperature variations on certain isobaric surfaces above the focal region of a strong earthquake were obtained and correlation coefficients $R$ were calculated in the troposphere above the center of the Sulaweski earthquake between the temperature series: $T_{950}$ and $T_{350}$ at isobaric levels of 950 and $350 \mathrm{hPa}, T_{350}$ and $T_{250}$ per levels 950 and $250 \mathrm{hPa}, T_{950}$ and $T_{250}$ at levels 950 and $250 \mathrm{hPa}$, the coefficient $R$ is positive and varies from 0.36 to 0.61 .

Consequently, in a disturbed atmospheric layer from 0.5 to $10 \mathrm{~km}$, temperature variations as a reaction to the influence of geophysical factors occur in a coordinated manner. The values of the coefficient $R$ between the temperature series $T_{950}$ and $T_{100}$ at 
isobaric levels of 950 and $100 \mathrm{hPa}, T_{250}$ and $T_{100}$ at levels of 250 and $100 \mathrm{hPa}$ are negative equal to -0.25 and -0.8 , respectively. The results obtained are consistent with the conclusions of [14].

To study the temperature field anomalies above the seismically active region focusing point during the geodynamic activity the method of constructing difference maps described in [13] was used. The methodology included the selection of data, the calculation of the temperature difference $T$ of the perturbed and unperturbed atmosphere and the construction of a map of the anomalous temperature field.

For the undisturbed atmosphere temperature data were selected when the seismic background in the studied region is calm. The conditions of the disturbed atmosphere are characterized by the temperature field $T$ during the intensification of seismic processes.

Examples of the spatio-temporal representation of temperature field anomalies at the isobaric level of $950 \mathrm{hPa}$ for September 20 (1), September 28 (2) and October 1 (3) are shown in Fig. 3, $a$. In Fig. 3, $a$ and Fig. 3, $b$ the dot indicates the epicenter, the solid ellipse is the focal region, the dotted ellipse is the preparation zone. Spatial-temporal images of temperature anomalies at the isobaric level of $100 \mathrm{hPa}$ for September 20 (1), September 28 (2) and October 1 (3) are shown in Fig. 3, b.

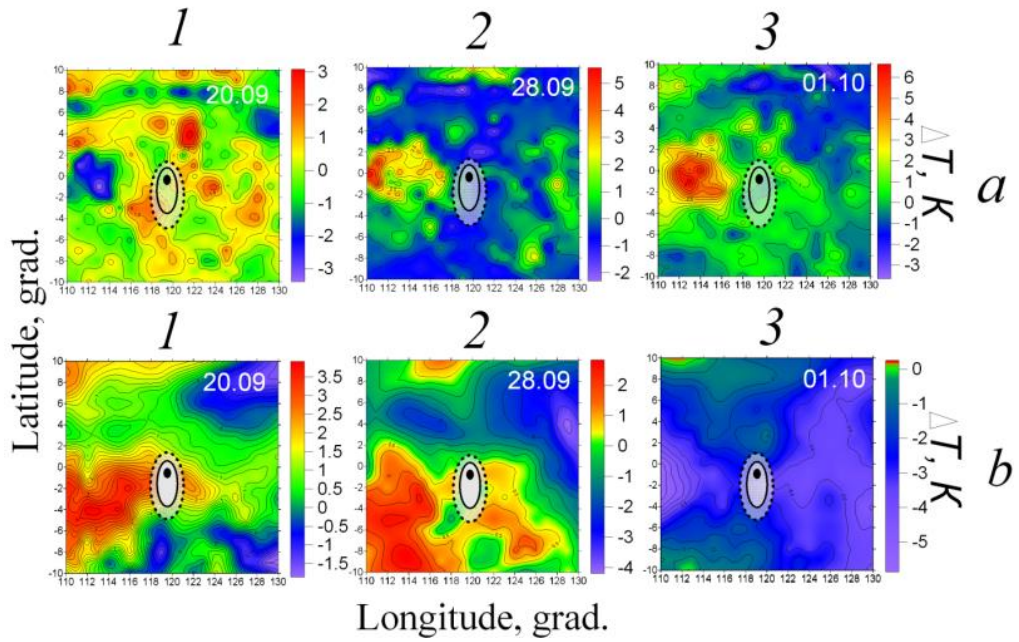

Fig. 3. Difference maps of temperature field anomalies at the levels of $950(a)$ and $100 \mathrm{hPa}(b)$ September 20 and 28, and October 1.

As can be seen in Fig. 3, $a$ and at the level of $950 \mathrm{hPa}$ above the seismically active region of the earthquake $\mathrm{M}=7,5$ (including the epicenter, focal region and preparation zone) on September 28 temperatures are below average. The focus at this level is located between two abnormal areas with elevated temperatures. Inside the focus the temperature $T$ is below average. An increase the parameter $T$ in the earthquake preparation zone occurred in early October.

At the isobaric level of $100 \mathrm{hPa}$ in the lower stratosphere (Fig. 3, b) over the studied seismically active region the projection of the focus is also between two anomalous regions with elevated temperatures. An increase in $T$ in the earthquake preparation zone at this level occurred in early October.

To detect temperature anomalies from remote sensing data we used the method for determining the temperature anomaly index, considered in [15].

In our work disturbances were detected in the temperature field over the seismically active region under study and a modified anomaly index $\delta T$ was calculated for temperature series at the most informative isobaric levels, taking into account the moment of the 
strongest earthquake and the studied time interval [16]. These levels were selected by the maximum correlation coefficient $R_{\max }$. Between the temperature series $T_{950}$ at the isobaric level of $950 \mathrm{hPa}$ and $T_{350}$ at the level of $350 \mathrm{hPa} R_{\text {max }}^{\prime}=0.56$. Between the temperature series $T_{250}$ at the isobaric level of $250 \mathrm{hPa}$ and $T_{100}$ at the level of $100 \mathrm{hPa} R^{\prime \prime}{ }_{\max }=-0.8$. The temperature profiles over the epicenter region of the earthquake with $M=7,5$ for 9 hours, the time closest to the moment of the main tremor, and for the period from September 21 to October 4 in 2017 were chosen as background values.

The graph of changes in the calculated index $\delta T$ for the time interval of the active existence of the Sulawes phenomenon on isobaric surfaces of 950 and $350 \mathrm{hPa}$ is shown in Fig. 4. The arrow indicates the date of the Indonesian earthquake.

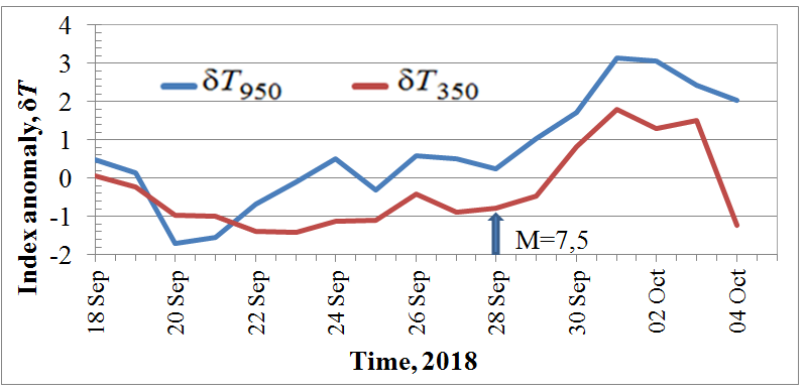

Fig. 4. Variations of the $\delta T$ index on isobaric surfaces of 950 and $350 \mathrm{hPa}$.

As can be seen in Fig. 4 the decrease in the $\delta T$ at $950 \mathrm{hPa}\left(\delta T_{950}\right)$ in the surface layer of the atmosphere at an altitude of $\sim 0.5 \mathrm{~km}$ occurred on September 20,8 days before the main shock of the strongest Indonesian earthquake. Index $\delta T$ at the level of $350 \mathrm{hPa}\left(\delta T_{350}\right)$ in the atmospheric layer at an altitude of $\sim 8 \mathrm{~km}$ decreased after 2 days, September 22. A consistent increase in the indices $\delta T_{950}$ and $\delta T_{350}$ is observed after the earthquake with $\mathrm{M}=$ 7,5. The parameters $\delta T_{950}$ and $\delta T_{350}$ reach their maximum values only by October 1 . The correlation coefficient between the series $\delta T_{950}$ and $\delta T_{350}$ is 0.78 .

In Fig. 5 shows a graph of the change in the calculated anomaly index $\delta T$ for the studied time interval at isobaric levels of 250 and $100 \mathrm{hPa}$. The arrow shows the date of the earthquake with $\mathrm{M}=7,5$.

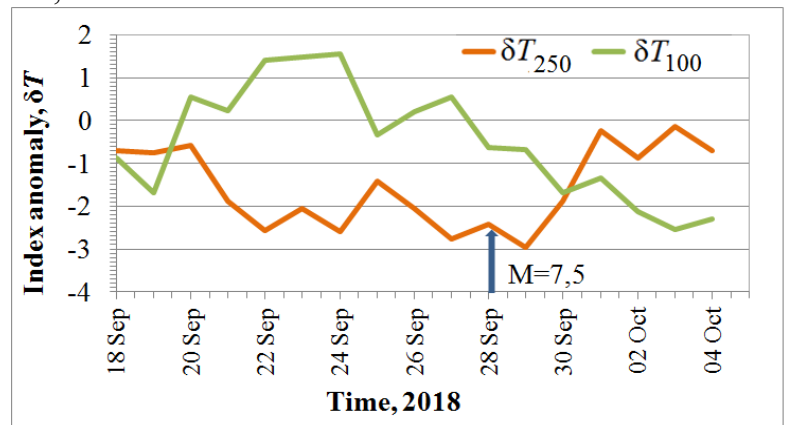

Fig. 5. Variations of the $\delta T$ index on isobaric surfaces of 250 and $100 \mathrm{hPa}$.

From Fig. 5 shows that the index $\delta T$ at the level of $250 \mathrm{hPa}\left(\delta T_{250}\right)$ in the atmosphere layer at an altitude of $\sim 10 \mathrm{~km}$ decreased after September 20,8 days before the main moment of the strongest earthquake. The index $\delta T$ at the level of $100 \mathrm{hPa}\left(\delta T_{100}\right)$ in the atmospheric layer at an altitude of $\sim 16 \mathrm{~km}$ also increased after September 20. A decrease in the index $\delta T_{100}$ is observed on September 27, a day before the earthquake with $M=7,5$. The increase in the index $\delta T_{250}$ occurs by October 1 . The correlation coefficient between the series $\delta T_{250}$ and $\delta T_{100}$ is -0.67 . 


\section{Conclusion}

The results showed that the application of the developed methodology for analyzing atmospheric disturbances during seismic activity allows us to identify temperature anomalies in the equatorial zone. It was found that in the troposphere above the epicentral region of the Indonesian earthquake with $\mathrm{M}=7,5$, anomalies with lower temperature values are observed and thermal anomalies with high temperature values are formed in the lower stratosphere during the study period.

\section{References}

1. J.R. Patton, S. Toda, R. Stein, V. Sevilgen, URL: http://temblor.net/earthquakeinsights/the-palu-koro-fault-ruptures-in-a-m7-5-quake-in-sulawesi-in.

2. H. Bao, J.-P. Ampuero, L. Meng, E. J. Fielding, C. Liang, C.W.D. Milliner, T. Feng, and H. Huang, Nature Geoscience, 12 (3) (2019).

3. C. Vigny, H. Perfettini, A. Walpersdorf, A. Lemoine, W. Simons, et al. J. Geophys. Res. 107 (B10. 2231) (2002).

4. A. Socquet, W. Simons, C. Vigny, R. McCaffrey, C. Subarya, D. Sarsito, B. Ambrosius, and W. Spakman, J. Geophys. Res. 111 (B08409) (2006).

5. USGS. URL: https://earthquake.usgs.gov

6. A. Socquet, J. Hollingsworth, E. Pathier, M. Bouchon, Nature Geoscience, 12 (2019).

7. IRIS. URL: https://ds.iris.edu/ds/nodes/dmc/data/types/events/catalogs/

8. H. Kanamori, E.E. Brodsky, Rep. Prog. Phys. 67 (2004).

9. Global Volcanism Program. Smithsonian Institution. URL: http://volcano.si.edu/volcano.cfm?vn=266030

10. C. G. Newhall, S. Self, J. Geophys. Res. 87 (C2) (1982).

11. NOAA. [Электронный pecypc]. - Access mode: URL: http://www.arl.noaa.gov/ready/cmet.html.

12. G. Goodrum, K. Kidwell, W. Winston, NOAA KLM user's guide. National Ocean and Atmosphere Administration. URL: http://www2. ncdc.noaa.gov/docs/klm/.

13. V. B. Kashkin, T.V. Rubleva, R.V. Odintsov, Journal of Siberian Federal University. Engineering and Technologies, 11 (8) (2018).

14. R. V. Odintsov, V. B. Kashkin, T. V. Rubleva, A. A. Romanov, I. V. Alekseenko, Sat. materials of the V International Scientific Conference "Regional Problems of Remote Sensing of the Earth" (September 11-14, 2018, Krasnoyarsk), Krasnoyarsk, Siberian Federal University (2018).

15. Yu.I. Shokin, N.N. Dobretsov, E.A. Mamash, V.A. Kikhtenko, P.V. Voronina, V.V. Smirnov, D.L. Chubarov, Computational technologies, 20 ( 5) (2015).

16. V. B. Kashkin, R. V. Odintsov, T. V. Rubleva, A. A. Romanov, K. V. Simonov, Trigger effects in Geosystems (Moscow, June 4-7, 2019): Materials of the $V$ International Conference / Ed. V.V. Adushkina, G.G. Kocharyan, IDG RAS, M. TORUS PRESS (2019). 